\title{
Engineering Application of Intrinsic Threshold Stress Intensity
}

\author{
R Sunder ${ }^{1}$ and Ramesh Koraddi ${ }^{1}$ \\ ${ }^{1}$ Bangalore Integrated System Solutions Pvt Ltd
}

May 5, 2020

\begin{abstract}
In atmospheric fatigue, intrinsic threshold stress intensity, $\mathrm{K}_{\mathrm{th}}$, far from being a material constant, varies significantly. It is controlled by a certain computable, load-history sensitive, near-tip residual stress, $\mathrm{s}^{*}$, that appears to moderate crack-tip diffusion kinetics and thereby determines $\mathrm{K}_{\mathrm{th}}$, the incremental $\mathrm{K}$ required for an open crack to extend by fatigue. This demands reconsideration of the relationship between near-threshold crack growth rates and applied effective stress intensity

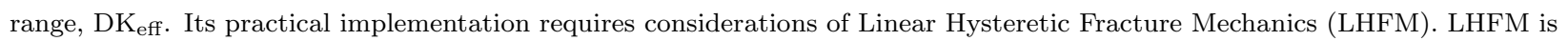
applied to translate applied K, to near-tip cyclic inelastic stress-strain response. A procedure is described to separate intrinsic threshold stress intensity from 'extrinsic' component for a known $\mathrm{DK}_{\mathrm{th}}$, obtained by conventional means. This opens the way to engineering application of the vast amount of available legacy fatigue threshold data obtained on long cracks by load shedding techniques. The new relationships permit extension of fracture mechanics considerations to short cracks including defects in additive manufactured materials and naturally forming cracks in components over high-cycle and very high-cycle (HCF/VHCF) regimes. Most importantly, the new approach permits handling near-threshold fatigue response both under constant amplitude as well as under variable-amplitude loading, representative of actual service conditions. It also permits re-interpretation of test data obtained by the so-called cyclic R-curve and compression-compression pre-cracking techniques.
\end{abstract}

\section{Introduction}

$\mathrm{da} / \mathrm{dN}$ versus $\Delta \mathrm{K}$ curves obtained using standard practices such as ASTM E647 [1] serve as vital inputs to comparative evaluation of materials in design trade-off studies, residual fatigue life analyses required to assess structural integrity, safe life and life between inspections as well as in fundamental research. The discovery of fatigue crack closure [2] and incorporation of algorithms for its estimation into standard test practice permitted correction for the stress ratio effect. A vital point on this curve is $\Delta \mathrm{K}_{\mathrm{th}}$, the threshold stress intensity range. Its estimation and interpretation remain controversial. This parameter is extremely crucial, particularly to applications involving extended endurance and long periods between inspections, i.e., to residual life estimates in HCF and VHCF regimes. Note also, that $\Delta \mathrm{K}_{\text {th }}$ may influence crack growth rates right up to $10^{-4} \mathrm{~mm} /$ cycle.

Engineering applications involve naturally forming cracks that grow under increasing stress intensity. Laboratory testing for $\Delta \mathrm{K}_{\text {th }}$ involves long cracks seeing load shedding. It obviously does not replicate conditions of practical interest. Long crack $\Delta \mathrm{K}_{\mathrm{th}}$ may not apply to naturally forming short cracks that are too short to see the consequences of certain 'extrinsic' factors [3]. Observed variations in laboratory estimates of $\Delta \mathrm{K}_{\mathrm{th}}$ as a function $\mathrm{K}_{\max }$ or stress ratio, $\mathrm{R}$, are typically attributed to these 'extrinsic' factors including fatigue crack closure due to plasticity, crack wake roughness and debris formation [3- 5]. Implicit in such understanding is the assumption that 'intrinsic' threshold stress intensity is a material constant and equal to a certain $\Delta \mathrm{K}_{\text {th,eff }}$ (that is devoid of the main extrinsic component, namely, crack closure). The actual break-up of $\Delta \mathrm{K}_{\text {th }}$ into its two supposed constituents has remained an enigma, given the lack of credible means to define, let alone, determineeither of the two. On the premise that the lowest possible $\Delta \mathrm{K}_{\text {th }}$ possible would represent a certain 
intrinsic property, different methods have been exercised in attempts to bridge the gap between laboratory test data and engineering application involving naturally forming cracks. The compression pre-cracking method is one of them $[6,7]$ and it is backed by numerical computations of crack closure as influenced by the process [8]. The so-called 'Cyclic R-Curve' is another method $[9,10]$. Both these methods follow from the consideration, that by inducing reversed yield at the crack initiator, the effective notch root stress ratio even under applied compression-compression loading will turn tensile, leading to closure-free conditions under subsequent tensile stress ratio. A much simpler method to resolve the issue has been suggested that assumes that $\Delta \mathrm{K}_{\text {th }}$ values obtained under high applied stress ratio will be associated with closure free conditions and therefore represent intrinsic component of $\Delta \mathrm{K}_{\mathrm{th}}$ [3]. Indeed, $\Delta \mathrm{K}_{\mathrm{th}}$ has been shown to progressively decrease with increasing applied stress ratio and $\mathrm{K}_{\max }$ [11-13]. However, it remains unclear, whether it eventually does plateau in support of the crucial assumption behind the method. After all, common to all these approaches is the presumption of intrinsic threshold stress intensity as a material constant.

The so called 'two parameter approach' may appear to be by far the simplest LEFM interpretation of crack growth rate all the way down to threshold [14-17]. According to this approach crack growth rate uniquely relates to a given combination of $\mathrm{K}_{\max }$ and $\Delta \mathrm{K}$. As $\mathrm{K}_{\max }$ approaches $\mathrm{K}_{\mathrm{c}}$, crack growth rate will obviously accelerate due to the increase of the quasi-static component. In the Paris Regime, the $K_{\max }$ effect can be traced to crack closure. And for reasons that are forthcoming, near-threshold crack growth rates are in addition, sensitive to $K_{\max }$ due to environmental action. In each of these stages, the very nature of the relationship between da/dN and the combination of $\mathrm{K}_{\max }$ and $\Delta \mathrm{K}$ will be different, being associated with vastly different mechanisms. Clearly, the two-parameter approach presents a rather simplistic picture of an extremely interesting, but complex phenomenon. A picture, that is rendered even more complex under random load history associated with engineering application.

Finally, engineering applications involve service load history that is seldom similar to constant amplitude conditions prescribed by standard testing practices such as ASTM E647. It is generally assumed that one or more of the load interaction models will handle the difference between the two. However, available computer software in industrial use ignores the effect of variable amplitude loading on fatigue thresholds. This restricts their potential usefulness to residual fatigue lives of the order of tens, or at best, a few hundred thousand load cycles. The current study describes the framework to render laboratory crack growth rate data over their entire range, right from threshold to fracture in a manner, that suits engineering application as well as serves the purpose of future research. Its focus is on intrinsic threshold stress intensity, $\mathrm{K}_{\mathrm{th}}$. and near-threshold fatigue crack growth rates.

The next section explains why atmospheric $\mathrm{K}_{\mathrm{th}}$, cannot be a material constant and identifies a computable parameter, in the form of near-tip residual stress, $\sigma^{*}$, to which $K_{\text {th }}$ has been found to be uniquely related $[18,1911$ Both references describe details of the testing practice to determine intrinsic threshold. However, in Ref. 18 , it is referred to as $\Delta \mathrm{K}_{\mathrm{th}}$, while we now refer to it as $\mathrm{K}_{\mathrm{th}}$ in order to differentiate it from the notation used in the literature that represents $\Delta \mathrm{K}_{\mathrm{th}}$ as the sum of intrinsic and extrinsic components.]. The envelope of $\sigma^{*}$ variation under both constant amplitude as well as variable amplitude loading, including the partial cases that represent cyclic R-curve and compression-compression loading conditions are described. This is followed by listing of $\mathrm{K}_{\mathrm{th}}$ versus $\sigma^{*}$ relationships for a variety of materials obtained in previous work. Additional data obtained in the course of this study on Ti-6Al-4V are presented. Based on these, a method is described to re-interpret legacy $\Delta \mathrm{K}_{\text {th }}$ data by splitting them into their intrinsic and extrinsic components, thus opening the way to extend available data bases obtained on long cracks to the case of naturally forming short cracks. These data are then collated along with data obtained at higher growth rates to describe a new equation for fatigue crack growth rate that may be more suitable for engineering application than currently available representations. The paper concludes with recommendations for future work related to both research as well as engineering application.

\section{Intrinsic Threshold for Atmospheric Fatigue Crack Growth}

A vast body of irrefutable fractographic evidence obtained under specially designed programmed load sequences confirms, that near-threshold crack growth rates exhibit significant load sequence sensitivity that 
cannot be explained by 'extrinsic' factors such as crack closure [20]. This effect recedes to vanishing proportions as growth rate increases into the Paris Regime. Early work revealed that the phenomenon does not appear to exist in high vacuum [21,22]. This prompted the Brittle Micro Fracture (BMF) theory of near-threshold crack extension, whereby the crack tip suffers Mode I micro-fracture by surface embrittlement from hydrogen in moisture at room temperature and oxidation at elevated temperature [23]. Such 'embrittlement' has been shown to be associated with highly localized slip [24, 25], that would imply Mode II micro fracture. Therefore, by 'brittle' the connotation is merely about localized accelerated crack extension. Note that in the context of this work, whether it is by Mode I or II would be immaterial. Research leading up to this new understanding of variable-amplitude fatigue is reviewed in Ref. 26.

If closure-free near-threshold crack growth rates are load sequence sensitive, it follows that the intrinsic component of $\Delta \mathrm{K}_{\mathrm{th}}$ cannot be treated as a material constant. If however, one can relate the intrinsic component to a certain near-tip stress at the commencement of the rising load half-cycle, one can search for a relationship between them. An experimental procedure was developed to characterize intrinsic (closure free) component $\mathrm{K}_{\mathrm{th}}$ over a wide range of highly controlled and computable near-tip residual stress conditions. It was initially validated on 2024-T3 Al-alloy [18], then fine-tuned and demonstrated on a variety of materials [19] including additive manufactured materials [27].
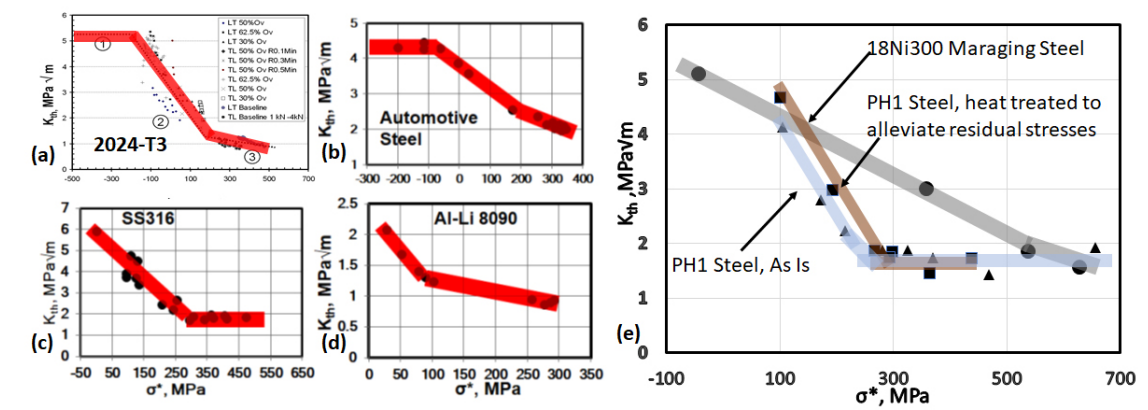

The new experimental procedure utilizes the consequences of near-tip stress-strain hysteresis to 'set' controlled values of a certain near-tip residual stress, $\sigma^{*}$, through periodic application of precision controlled periodic overload/underload sequences, while at the same time decreasing $\Delta \mathrm{K}$ with crack extension, with $\mathrm{P}_{\max }=$ Const, until threshold conditions conforming to $10^{-7} \mathrm{~mm} /$ cycle are reached. Test conditions may also include 'no overload' conditions, as the means to impose higher tensile values of $\sigma^{*}$. The magnitude of tensile overload is restricted to preclude the possibility of crack closure, whose absence is independently confirmed per ASTM E647. Also, crack extension during the periodic overloads constitutes a negligible fraction of baseline crack growth. The resultant threshold $\Delta \mathrm{K}$ denoted as $\mathrm{K}_{\mathrm{th}}$ qualifies as 'intrinsic'. The absence of extrinsic component is confirmed by ensuring that $\mathrm{K}_{\min }$ registered at threshold is well in excess of $\mathrm{K}_{\mathrm{op}}$ measurement from unloading compliance made with most unconservative settings.

A fully automated test procedure permits determination of the $\mathrm{K}_{\mathrm{th}}$ versus $\sigma^{*}$ relationship from a limited number of test coupons $[18,19]$. As shown in Figs. 1a-e, test data from a variety of materials tested suggest a unique relationship between $K_{\text {th }}$ and $\sigma^{*}[18,19,27]$. The wide range of possible cycle-sequence sensitive variation in $K_{\text {th }}$ points to its potential in determining residual fatigue life under service loading conditions in the HCF/VHCF range. These findings underscore limitations of prevailing standard testing practice.

It is important to note, that near-tip residual stress, $\sigma^{*}$, is sensitive to cyclic inelastic response well within the cyclic plastic zone, virtually, a crack-tip response. It is not synonymous and in fact, has little in common with 'residual stress' inferred by the well-known Wheeler [28] and Willenborg [29] crack growth retardation models that refer to the compressive residual stress caused by the stretchedmonotonic plastic zone after a tensile overload. Also, it is unrelated to the distributed residual stress that can occur by material processing [30, 31]. These 'macroscopic' residual stress distributions will affect crack closure as the crack wake will develop 
within their region of influence. However, the crack tip stress response will be the consequence of superposed action of such residual stress combined with that of actual cycle-by-cycle loading. This is illustrated by the $\mathrm{K}_{\mathrm{th}}$ versus $\sigma^{*}$ relationships seen for AM specimens from PH1 steel, that were tested with and without heat treatment to remove residual stress (Fig. 1e). We can see a small but noticeable parallel shift in the relationship, but at higher $\sigma^{*}$, the two data sets merge into a flat (almost constant value), suggesting that AM-related residual stress in the material had little effect on lowest $K_{t h}$. This may be the consequence of 'flattening out' of the monotonic near-tip stress versus K curve, or, due to a certain 'saturation' in the effect of $\sigma^{*}$ on $\mathrm{K}_{\mathrm{th}}$. Interestingly, a similar flattening of response at the lower bound is also seen in test data from the other stainless steel, SS 316 that was tested (Fig. 1c).

\section{Near-Tip Stress Response and Intrinsic Threshold Stress Intensity, $K_{\text {th }}$}

The connection between near-threshold fatigue crack growth and crack-tip diffusion kinetics has been highlighted in early work $[32,33]$. The unique relationship between $\mathrm{K}_{\mathrm{th}}$ and $\sigma^{*}$ underscores the obvious influence of instantaneous near-tip stress on diffusion kinetics, and consequently of the effect of $\mathrm{K}_{\max }$ and particularly, of load history, two key aspects overlooked in early work that have a crucial bearing on engineering application.

\begin{tabular}{|c|c|c|c|}
\hline $\begin{array}{c}\mathbf{r}^{*} \\
(\mathbf{m m})\end{array}$ & $\begin{array}{c}\mathbf{E} \\
(\mathbf{G P a})\end{array}$ & $\begin{array}{c}\mathbf{K}^{\prime} \\
(\mathbf{M P a})\end{array}$ & $\mathbf{n}^{\prime}$ \\
\hline 0.1 & 73.1 & 736 & 0.13 \\
\hline & & \\
\hline & \multicolumn{2}{|}{$r^{*}$}
\end{tabular}

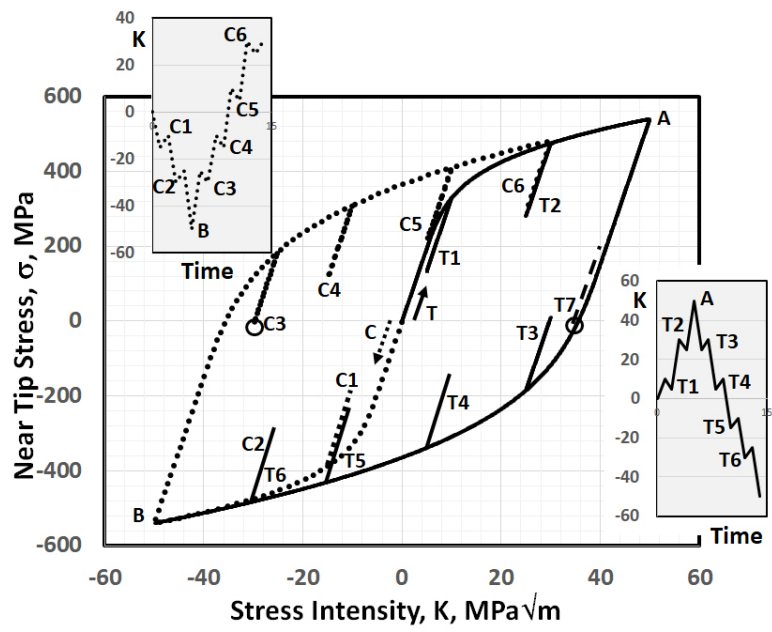

Consideration of stress very close to the crack tip requires what may be referred to as a Linear Hysteretic Fracture Mechanics or LHFM approach in order to account for cycle-sequence sensitivity of near-tip stress to applied K-history. Equations associated with Linear Elastic Fracture Mechanics (LEFM) ignore neartip cyclic inelastic response. LHFM overcomes this shortcoming by describing near-tip cyclic stress-strain hysteretic response even if K-values may conform to Linear-Elastic considerations. In the process, near-tip local stress history can be rendered as a function of applied stress intensity history given by equations whose description is forthcoming. Rendering $\sigma^{*}$ at $\mathrm{K}_{\min }$ as a unique function of $\mathrm{K}$-history leaves strain response irrelevant to near-threshold fatigue even if it may retain its 'mechanistic' significance from considerations of crack closure, crack-tip blunting, etc.

Fig. 2 explains the framework connecting cyclic stress-strain properties, applied load history, near-tip stress response to the applied load history including $\sigma^{*}$ at the commencement of embedded load cycles of nearthreshold magnitude and the experimentally established relationship between $\sigma^{*}$ and intrinsic threshold stress intensity, $\mathrm{K}_{\mathrm{th}}$. The data and calculations are for 2024-T3 Al-alloy, but the same framework would be applicable for any other metallic material exhibiting strain hardening properties. The figure shows variation of near-tip stress, $\sigma$, computed for two sequences of applied stress intensity, K, for the case of a fully open fatigue crack and at a distance $\mathrm{r}^{*}$. It is assumed that the crack wake will not close even in compression, a situation that is generally attempted to be reproduced in tests with compression-compression pre-cracking 
[6,7] and in cyclic R-curve experiments [9, 10]. Near-tip response is plotted for two applied K-sequences. One sequence commenced in the tensile direction, while the other marked with the dotted line, did so in the compressive direction. The two sequences include a tensile and compressive overload marked as A and B respectively. These together form an envelope of near-tip stress response that effectively determines potential variation of $\sigma^{*}$ for any given position of an embedded near-threshold load cycle. The material constants shown in the figure and the $\mathrm{K}_{\mathrm{th}}$ versus $\sigma^{*}$ data points were obtained on $5 \mathrm{~mm}$ thick $\mathrm{C}(\mathrm{T})$ specimens cut from 2024-T3 [18]. These, together with the three equations below were adequate to compute the graph of $\sigma$ versus $\mathrm{K}$ sequence shown:

$$
\begin{gathered}
K_{1}=\sqrt{2 \pi r^{*} E \sigma_{1}\left[\frac{\sigma_{1}}{E}+\left(\frac{\sigma_{1}}{K^{\prime}}\right)^{\frac{1}{n \prime}}\right]} \\
K_{1}-K_{2}=\sqrt{2 \pi r^{*} E\left(\sigma_{1}-\sigma_{2}\right)\left[\frac{\sigma_{1}-\sigma_{2}}{E}+2\left(\frac{\sigma_{1}-\sigma_{2}}{2 K^{\prime}}\right)^{\frac{1}{n}}\right]} \\
\left.K_{3}-K_{2}=\sqrt{2 \pi r^{*} E\left(\sigma_{3}-\sigma_{2}\right)\left[\frac{\sigma_{3}-\sigma_{2}}{E}+2\left(\frac{\sigma_{3}-\sigma_{2}}{2 K^{\prime}}\right)^{\frac{1}{n,}}\right.}\right]
\end{gathered}
$$

where,

$\mathrm{K}_{1}$ represents starting $\mathrm{K}$-excursion from zero and following the monotonic material response, while $\mathrm{K}_{2}$ and $\mathrm{K}_{3}$ are subsequent applied $\mathrm{K}$ values assumed to be following the cyclic stress-strain response associated with reversed strain and $\sigma_{1}-\sigma_{3}$ are associated near-tip stress, E is Young's Modulus, K' is cyclic strength coefficient, n' is cyclic strain hardening exponent and $\mathrm{r}^{*}$ is the distance from the crack tip at which local stress, $\sigma$ is computed.

Note that each equation represents an excursion, whose sign would need to be inverted in the case of initial compressive excursion (the dotted line in Fig. 2). The solution of eq. (1) determines $\sigma_{1}$. Similarly, solving eq. (2) determines $\sigma_{2}$, while $\sigma_{3}$ is determined by solving eq. (3).

The interruptions T1-T6 and C1-C6 are of equal magnitude and set to $5 \mathrm{MPa}[?] \mathrm{m}$ to match the highest $\mathrm{K}_{\text {th }}$ seen in the $K_{\text {th }}$ versus $\sigma^{*}$ relationship for this material (Fig. 1a). The $\sigma^{*}$ value corresponds to the minimum $\mathrm{K}$-value in each of the $5 \mathrm{MPa}[?] \mathrm{m}$ excursions seen. Three sets of near-threshold cycles have such minima at $-30,-15,5$ and $25 \mathrm{MPa}[?] \mathrm{m}$ respectively. Of these, $\sigma^{*}$ for two, namely, $\mathrm{C} 1, \mathrm{C} 2$ can be computed from eq. (1) alone. For $\mathrm{T} 1-\mathrm{T} 6, \sigma^{*}$ requires solution of eqs. $(1,2)$. Estimation of $\sigma^{*}$ for $\mathrm{C} 3$-C6 requires solution of eqs. (1-3).

The computed $\sigma^{*}$ values are suggestive of the corresponding $\mathrm{K}_{\text {th }}$ value as seen from the $\mathrm{K}_{\mathrm{th}}$ versus $\sigma^{*}$ plot in Fig. 1a. The relationship between $\mathrm{K}_{\mathrm{th}}$ and $\sigma^{*}$ being unique, it does not matter, what was the associated applied stress intensity. What mattered, was the LHFM-driven near-tip stress response to the applied Ksequence as estimated from eqs. (1-3). Note however, that the computations shown are assuming $\mathrm{r}^{*}=0.1$ $\mathrm{mm}$. At this distance from the crack tip, elastic unloading over $5 \mathrm{MPa}[?] \mathrm{m}$ induces a local stress change of approximately $100 \mathrm{MPa}$. This is about $35 \%$ less than at $\mathrm{r}^{*}=0.035 \mathrm{~mm}$ that was used in [18]. Therefore, the $\mathrm{K}_{\text {th }}$ versus $\sigma^{*}$ relationship in the figure cannot be directly related to the $\sigma$ versus $\mathrm{K}$ plot shown. There will be a horizontal shift in the $\mathrm{K}_{\mathrm{th}}$ versus $\sigma^{*}$ relationship induced by the difference in $\sigma^{*}$ due to elastic unloading and also a small vertical shift due to enhanced response to overloads A, B. Trends however, will remain unchanged.

Excursions T3-T6 will see the influence of overload A followed by the unloading to their respective minima. Likewise, C3-C6 will see the consequence of compressive overload B followed by tensile reloading.

Note that the four sets of three identical applied stress-intensity excursions, i.e., (C2,C3,T6), (C1,C4,T5), $(\mathrm{T} 1, \mathrm{~T} 4, \mathrm{C} 5)$, and $(\mathrm{T} 2, \mathrm{~T} 3, \mathrm{C} 6)$ will see vastly different near-tip stress at the commencement of the rising load 
excursion. As a consequence, they will see vastly different $\mathrm{K}_{\text {th }}$ values in atmospheric fatigue (refer to Fig. 1a). The cycle pairs $(\mathrm{C} 2, \mathrm{~T} 6),(\mathrm{C} 1, \mathrm{~T} 5),(\mathrm{C} 5, \mathrm{~T} 1)$ and $(\mathrm{C} 6, \mathrm{~T} 2)$ reached their commencement through vastly different load history, yet end up with minor deviation in $\sigma^{*}$. These will therefore see correspondingly similar $\mathrm{K}_{\text {th }}$ values. Note also, that cycles C3 and T3 are vastly different in terms of applied mean stress intensity, yet, $\sigma^{*}$ in the two are not as vastly different as between identical applied cycles, e.g., C1, C4. These differences cannot be discerned by LEFM analysis. Application of LHFM to cycle-by-cycle stress-K analysis brings out the observed differences, with the added promise of opening up the possibility of modeling near-threshold variable amplitude fatigue crack growth.

Test conditions enforced by prevailing standard practice maintaining either stress ratio, $\mathrm{R}$, or, $\mathrm{K}_{\max }$ constant essentially restricts $\sigma^{*}$ to a narrow band without necessarily freezing the extrinsic component. These two parameters have little bearing on thresholds experienced under load sequences of engineering importance. Compelling evidence in this regard emerges from a cursory comparison of load cycle $\mathrm{C} 3\left(\mathrm{~K}_{\max }=-25 \mathrm{MPa}[?] \mathrm{m}\right)$ with a hypothetical load cycle $\mathrm{T} 7$ with $\mathrm{K}_{\max }$ of $40 \mathrm{MPa}[?] \mathrm{m}$. One of these cycles is in compression, the other in tension and separated by a difference of $65 \mathrm{MPa}[?] \mathrm{m}$. Nevertheless, both will see the same $\mathrm{K}_{\mathrm{th}}$. If estimated $\Delta \mathrm{K}_{\text {th }}$ for the two cycles does differ as it is quite likely to, the difference may only be attributable to the extrinsic fraction of $\Delta \mathrm{K}_{\mathrm{th}}$.

The envelope formed by the near-tip stress response to tension-compression K-history is limited by the stress associated with highest overload and underload. The lower bounding curve in this case indicates the lowest possible $\sigma^{*}$ at any given applied $\mathrm{K}_{\mathrm{min}}$. It determines $\sigma^{*}$ for any load cycle 'standing' on the lower bound. The envelope illustrates the potential variation in $\sigma^{*}$ depending on applied load history. Obviously, this margin will be controlled by strain hardening exponent, n', and the magnitude of extreme variations in loading. For the sequences in the figure, the margin of potential variation in $\sigma^{*}$ for identical applied cycle in terms of $\mathrm{K}_{\max }$ and $\mathrm{K}_{\min }$ is of the order of $400 \mathrm{MPa}$. Judging from the $\mathrm{K}_{\mathrm{th}}$ versus $\sigma^{*}$ relationship, this can induce significant load-history dependent variation in $\mathrm{K}_{\mathrm{th}}$. Thus, cycles $\mathrm{C} 3$, C4 will see lower $\mathrm{K}_{\mathrm{th}}$ values thanks to the compressive overload B, while cycles T3, T4 will see higher $\mathrm{K}_{\text {th }}$ than cycles T1, T2, thanks to the overload $\mathrm{A}$. This is a direct consequence of near-tip cyclic stress-strain hysteresis. It has nothing to do with crack closure, in fact, crack closure would inhibit such hysteretic response.

With increase in the magnitude of interruptions T1-T6, C1-C6, the minimum stresses in these cycles will approach the lower bound of the outer loop, reducing the variation in $\sigma^{*}$ within each set. Simultaneously, as $\Delta \mathrm{K}$ during these cycles is large enough to cause greater crack extension, closer to the Paris Regime $(>$ $10^{-4} \mathrm{~mm} /$ cycle), the associated mechanism change in crack extension will render any remaining variation irrelevant, and also effectively render LHFM considerations redundant.

The near-tip stress versus applied stress-intensity plot can assist in re-interpreting available test data to understand material response to the test procedures followed in compression-compression pre-cracking and from cyclic R-curve testing. Both these strictly speaking, involve variable amplitude loading. In order to determine the $\mathrm{K}_{\text {th }}$ fraction from $\Delta \mathrm{K}_{\text {th }}$ estimated using these methods, one would need to model $\sigma^{*}$ as a function of the applied load history in the course of compression-compression pre-cracking and cyclic R-curve testing. A similar procedure can be followed to re-interpret the vast collection of legacy threshold data using the procedure described below.

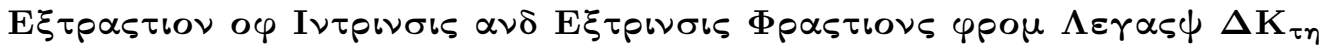

Industrial applications involving both Safe-Life as well as Fail-Safe design rely on a vast data base of $\Delta K_{\text {th }}$ values obtained over several decades of application of standard testing practices such as ASTM E647. Fatigue design using the Kitagawa-Takahashi approach requires intrinsic threshold inputs to assign permissible design stress levels because it addresses naturally forming cracks that are unlikely to experience closure [34]. Research effort to understand intrinsic threshold response using innovative methods such as compressioncompression pre-cracking and cyclic R-curve methods has come up with numbers that are likely to benefit from calibration against reliable $\mathrm{K}_{\text {th }}$ values, duly accounting for load history. Separation of the intrinsic and extrinsic components for available $\Delta \mathrm{K}_{\text {th }}$ data therefore serves important practical purposes. 
Determination of the extrinsic component at threshold is also crucial to calibrate analytical crack closure models for threshold conditions. Currently, there is no credible experimental method to characterize closure component at threshold. Estimation of this component may hold the key to modeling the differences in evolution of closure under laboratory load shedding as opposed to how it proceeds in the case of naturally forming cracks. The stumbling block comes by way of the inability to unambiguously separate the extrinsic and intrinsic fractions of $\Delta \mathrm{K}_{\mathrm{th}}$. The uniqueness of the $\mathrm{K}_{\mathrm{th}}$ versus $\sigma^{*}$ relationship can serve as a platform to overcome this roadblock. A method is described below to extract the intrinsic fraction from a given $\Delta K_{\text {th }}$ estimate, provided of course the $\mathrm{K}_{\text {th }}$ vs $\sigma^{*}$ relationship for the material is known.

Consider near-tip stress response to an applied stress intensity excursion under a near-threshold load cycle as applicable in conventional testing practice as per ASTM E647. There are three possible routes to reach the cycle in question. One is with constant applied stress ratio, $\mathrm{R}$, but with decreasing $\Delta \mathrm{K}$. The second is with $\mathrm{K}_{\max }=$ Const and $\mathrm{K}_{\min }$ steadily increasing to the point of threshold. The third is with $\mathrm{P}_{\max }=$ Const, but with $\mathrm{P}_{\min }$ increasing rapidly enough to induce decreasing $\Delta \mathrm{K}$ towards threshold. The first of these involves a steadily decreasing monotonic plastic zone and is therefore sensitive to the possibility of increased closure as the extent of plastic wake will be always greater than the extent of plastic deformation ahead of the crack tip. Both the first and second technique involve periodic discrete drop in maximum load at the next load shedding and this can affect near-tip residual stress from elastic unloading. The last technique is rate insensitive when viewed in terms of monotonic plastic zone as well as near-tip residual stress as can be readily establish by simulation of near-tip stress response using eqs. (1-3). Thus, irrespective of the rate of decrease in $\Delta \mathrm{K}$, monotonic plastic zone size will always increase. Obviously, for a given $\mathrm{K}_{\max }$ and $\Delta \mathrm{K}, \mathrm{K}_{\mathrm{op}}$ cannot be expected to be the same for the three cases. However, considering a fully open crack at $K_{\max }$, one may assume that near-tip stress at $K_{\max }$ will be the same and given by the solution of eq. (1).

The near-tip stress excursion associated with unloading as given by eq. (2) will depend on $\Delta \mathrm{K}$ restricted by the onset of crack closure that serves as the 'extrinsic' factor acting through crack wake residual tensile plastic strains, debris, surface roughness, etc, those factors that are deemed absent in the event of natural crack formation. Irrespective of the applied stress ratio and irrespective of the extent of these extrinsic factors, a unique relationship may be assumed between near-tip unloading in terms of near-tip stress, $\sigma^{*}$, and a certain $\mathrm{K}_{\mathrm{op}}$ or $\mathrm{K}_{\mathrm{min}}$, whichever is greater, at which near-tip stress response will cease.

Neglecting near-tip stress response at $\mathrm{K}<\mathrm{K}_{\mathrm{op}}$, a certain $\mathrm{R}_{\text {eff }}$ will apply, for which, a unique relationship will exist between $\sigma^{*}$ and $\Delta \mathrm{K}_{\mathrm{eff}}$, that is similar to the one for a fully open crack with $\mathrm{R}=\mathrm{R}_{\mathrm{eff}}$. If one plots the relationship between $\sigma^{*}$ and $\Delta K_{\text {eff }}$ for a wide range of $R_{\text {eff }}$ on the same plot that relates $K_{\text {th }}$ as a function of $\sigma^{*}$, one can map the intersection of each such curve with the trend line relating $K_{\text {th }}$ to $\sigma^{*}$. The intersection points thus obtained will determine the $\mathrm{R}_{\text {eff }}$ associated with $\mathrm{K}_{\mathrm{th}}$ at the intersection point. Obviously, in so doing, care must obviously be taken to ensure that the same values of $\mathrm{r}^{*}, \mathrm{E}, \mathrm{K}^{\prime}$ and n' are used for both sets of data points. $\mathrm{K}_{\max }$ associated with $\mathrm{K}_{\mathrm{th}}$ at the intersection point is readily determined from $\mathrm{R}_{\mathrm{eff}}$, as $\mathrm{K}_{\max }$ $=1 /\left(1-R_{\text {eff }}\right)$.

Now that we have a set of data points relating $K_{\text {th }}$ to $K_{\max }$, these can be plotted together with available $\Delta \mathrm{K}_{\text {th }}$ against $\mathrm{K}_{\max }$ obtained using conventional testing practice per ASTM E647. On such a plot, $\mathrm{K}_{\mathrm{th}}$ being an intrinsic value, its relationship with $K_{\max }$ will necessarily lie below the $\Delta K_{\text {th }}$ versus $K_{\max }$ relationship. The $K_{\text {th }}$ versus $K_{\max }$ relationship effectively splits the area under the $\Delta K_{\text {th }}$ versus $K_{\max }$ relationship into two areas. The upper area reflects the extrinsic fraction of threshold response, while the lower one reflects the intrinsic fraction.

Under constant amplitude loading, $\sigma$ at $\mathrm{K}_{\max }$ is quite independent of the presence of an extrinsic component by way of crack closure or for other reasons, as long as these do not impact crack-tip response at $\mathrm{K}_{\max }$. The same cannot be said of $\sigma^{*}$ at $\mathrm{K}_{\min }$. Hence, $\mathrm{K}_{\mathrm{th}}$ by definition, cannot be correlated against $\mathrm{R}$. However, as $K_{\max }$ at threshold and $R$ are inevitably related when prevailing testing practice is uniformly applied, a misleading 'appearance of a relationship' is likely to emerge if one plots $K_{t h}$ versus $R$ for constant amplitude loading conditions. 
In principle, the above method to identify intrinsic and extrinsic fractions of $\Delta \mathrm{K}_{\text {th }}$ may be readily applied to any type of constant amplitude loading prevailing at the point of threshold, provided, near-tip stress at $\mathrm{K}_{\max }$ can be treated as the same as in the event of a crack with growing or constant plastic zone size. As long as this condition is met by other test conditions such as cyclic R-Curve and compression-compression precracking the assumptions behind the method carry validity. Thus, if $\Delta \mathrm{K}_{\mathrm{th}}$ estimated by these two methods is the same as $\mathrm{K}_{\mathrm{th}}$ derived for the same tests, one may be assured that they indeed yielded intrinsic threshold conditions. If $\Delta \mathrm{K}_{\mathrm{th}}>\mathrm{K}_{\mathrm{th}}$, the difference would be indicative either of partial crack closure, or, of history effects leading to variations in $\sigma^{*}$. Thus, in the unlikely event $\Delta K_{\text {th }}<K_{\text {th }}$, given the unique nature of the $\mathrm{K}_{\mathrm{th}}$ versus $\sigma^{*}$ relationship, the only possibility is that test conditions induced $\sigma^{*}$ values exceeding the value estimated by eq (1-2).

\section{Example of Separation of Intrinsic and Extrinsic Fractions in Legacy Data}
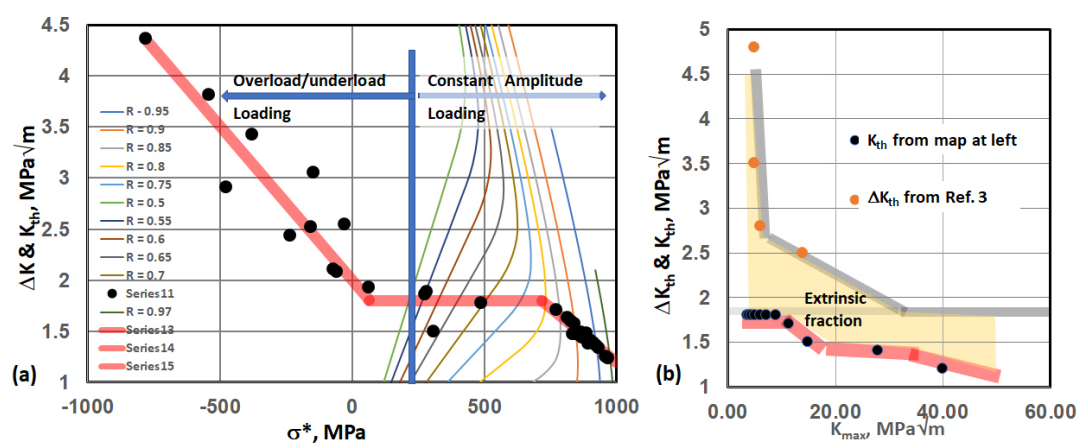

Results of an exercise in determining the intrinsic and extrinsic fractions of $\Delta K_{\text {th }}$ are summarized in Fig 3 and demonstrate how the relationship between $\mathrm{K}_{\mathrm{th}}$ and $\sigma^{*}$ can be used to re-interpret and thereby add value to legacy threshold data. These results pertain to Ti-6Al-4V alloy. Fig. 3a shows the $\mathrm{K}_{\text {th }}$ versus $\sigma^{*}$ relationship obtained on $5 \mathrm{~mm}$ thick $50 \mathrm{~mm}$ wide $\mathrm{C}(\mathrm{T})$ specimens using the procedure described in [19]. Also shown on the same figure is a map of computed $\Delta \mathrm{K}_{\text {eff versus }} \sigma^{*}$ for different $R_{\text {eff }}$ values. The intersection point of each line with the $K_{\text {th }}$ versus $\sigma^{*}$ trend line reveals the $R_{\text {eff }}$ associated with the $K_{\text {th }}$ at that point. This leads to determination of the associated $\mathrm{K}_{\max }$ and results in forming the curve in Fig. 3b, relating $\mathrm{K}_{\max }$ to $\mathrm{K}_{\mathrm{th}}$. Also shown in Fig. $3 \mathrm{~b}$ are the legacy $\Delta \mathrm{K}_{\mathrm{th}}$ versus $\mathrm{K}_{\max }$ data points. Thus, the $\mathrm{K}_{\max }$ versus $\mathrm{K}_{\mathrm{th}}$ curve serves as the partition between intrinsic and extrinsic fractions of $\Delta \mathrm{K}_{\mathrm{th}}$.

An important point of note is the relatively small variation in $\mathrm{K}_{\text {th }}$ between 1.25 and $2 \mathrm{MPa}$ [?]m as a function of $\mathrm{R}_{\text {eff }}$ under constant amplitude loading for this material. Compare this with a substantial further increase in $K_{t h}$ that is solely due to the effect of load sequence on $\sigma^{*}$. This underscores the sensitivity of $K_{t h}$ to load history, a phenomenon that has received little attention in the literature even if it may significantly impact engineering application. Obviously, tensile constant amplitude load conditions by their very nature, can only leave behind tensile residual stress at the crack tip. However, a tensile overload is capable of inducing compressive near-tip residual stress that, by retarding diffusion kinetics, 'cheats' the crack tip into believing it is growing in vacuum. This also implies that there is a certain maximum $\mathrm{K}_{\mathrm{th}}$ that cannot be exceeded, that would be associated with high vacuum [18]. 

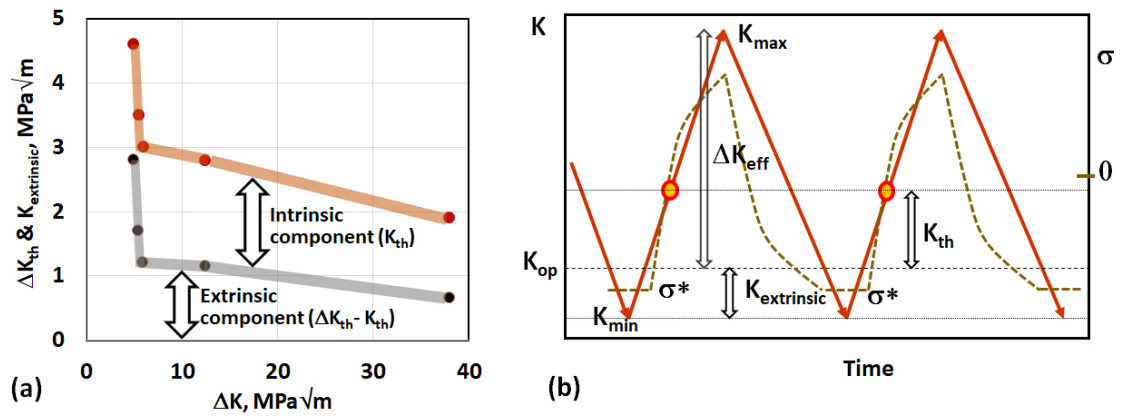

In Fig 3b, the intrinsic fraction occupies the lower portion of the graph, while the extrinsic fraction representing the difference between known values of $\Delta \mathrm{K}_{\mathrm{th}}$ and $\mathrm{K}_{\mathrm{th}}$ sits at the top. A more appropriate representation of the fractions appears in Fig. 4a, which shows the same data rearranged with extrinsic fraction below and the intrinsic fraction at the top. This constitutes a more realistic representation of actual fatigue crack tip response to a rising load half cycle starting from $K_{\min }$ as shown in Fig. 4b. On this graph, near-tip stress variation is shown as broken line. At $\mathrm{K}_{\min }$, the crack wake may be shielding the crack tip from the increasing applied stress intensity. Note that the stress response to incremental $\mathrm{K}$ commences only at $\mathrm{K}_{\mathrm{op}}$, where the extrinsic component reduces to zero at the intermediate line. This is illustrated by the flat segment of the stress response curve. Once near-tip stress response is activated, a certain threshold incremental stress intensity is required for threshold crack extension. Obviously, this intrinsic component represented by $\mathrm{K}_{\mathrm{th}}$ will depend on $\sigma^{*}$ at the commencement of each loading half cycle.

Obviously, for a naturally forming crack subject to constant amplitude loading, the bottom region shown in Fig. 4a will be subject to a certain transitional evolutionary process associated with the build-up of extrinsic component, largely, crack closure. It will be totally absent for a naturally forming crack and gradually increase with wake development. Note that these are incremental, not absolute values. Therefore, for a long crack, the extrinsic component appears disproportionately large at lower $\Delta \mathrm{K}$. Also, a point of note in this regard is the restricted applicability of LHFM considerations to a very short crack. Near-tip stress is computed on the assumption of the validity of LEFM for estimates of K. At very small crack sizes, the near-tip stress field becomes sensitive to the magnitude of applied stress. Therefore, at least as a first approximation, one may need to correct $\sigma^{*}$ for applied stress in estimates of $\mathrm{K}_{\mathrm{th}}$.

The scheme of data as illustrated in Fig. 4 serves to understand near-threshold fatigue crack growth not only under constant amplitude, but also, under variable-amplitude loading that is necessary for engineering application. Thus, $\mathrm{K}_{\mathrm{op}}$ representing the extrinsic fraction will be determined by the evolution of the crack wake as well as its interaction with crack tip blunting momentarily caused by tensile overloads and compressive squeeze beyond yield caused by underloads. Thus, blunting will momentarily eliminate the extrinsic fraction, while a compressive overload will reduce it. In both cases, the reduction will be instantaneously. However, increase in the extrinsic (closure) component cannot occur without crack extension and build-up of new wake. On the other hand, near-tip hysteretic stress-strain response can induce dramatic cycle-sequence sensitive variation in $\sigma^{*}$ that in turn will affect the intrinsic component, $\mathrm{K}_{\mathrm{th}}$ over the next rising load half cycle.

For Ti-6Al-4V, it is generally assumed that the extrinsic component is associated with surface roughness induced crack closure that is restricted to a maximum of 2 to $3 \mathrm{MPa}[?] \mathrm{m}$ [3] in absoluteterms. By implication, once $\mathrm{K}_{\min }$ exceeds this level, the extrinsic component should disappear. Note however, that at even at the highest possible $\mathrm{K}_{\max }$ at which $\Delta \mathrm{K}_{\text {th }}$ data are available, the lowest recorded $\Delta \mathrm{K}_{\mathrm{th}}=1.9 \mathrm{MPa}[?] \mathrm{m}$ [3], while the lowest registered $\mathrm{K}_{\mathrm{th}}$ in our experiments was $1.24 \mathrm{MPa}[?] \mathrm{m}$. The $\Delta \mathrm{K}_{\mathrm{th}}=1.9 \mathrm{MPa}[?] \mathrm{m}$ readout corresponds to a $\mathrm{R}=0.95$, suggesting a certain extrinsic component of about $0.66 \mathrm{MPa}[?] \mathrm{m}$ even at such a high stress ratio. One may conclude that the extrinsic value carries a relative magnitude, with $\mathrm{K}_{\min }$ always serving as the point of reference. 
LEFM assumes $\mathrm{d} \sigma / \mathrm{dK}=$ Const. Given the combined Mode I / II crack opening displacement response, a rough wake surface may somewhat attenuate the partial derivative $d \sigma / d K$, as applied $K$ approaches $K_{\min }$. This is because crack closure is not instantaneous. Rather, it is a process that occurs over a segment of variation in $\mathrm{K}$, either because of non-uniform contact across the crack front, or, due to friction between sliding surfaces, or, as a combination of the two. Such an attenuation may not have been present in our experiments to determine $K_{t h}$ because, irrespective of the applied stress ratio, periodic crack size measurements always involved unloading to near-zero, that is likely to 'squeeze out' wake influence at least at higher (baseline) stress ratio.

Under variable amplitude loading, both the extrinsic as well as the intrinsic component will vary with crack extension as well as under the influence of applied load history. Build-up of crack wake will be strongly influenced by the size of the plastic zone left behind by the highest loads in a random sequence. The wake is likely to be squeezed into compressive yield by severe compressive overloads, thereby reducing crack closure until fresh wake is developed. Finally, a new tensile overload can leave the crack tip blunted and momentarily remove crack closure altogether. All three will induce changes into the extrinsic fraction of $\Delta K_{\text {th }}$ that needs to be handled by analytical modeling of closure. The near-tip stress on the other hand is a 'cycle-sequence' sensitive variable. It will see the consequence of near-tip cyclic inelastic response and under a random load sequence, will effectively see significant, cycle-by-cycle variation while the crack is fully open. If the crack remains partially closed during a load sequence, $\sigma^{*}$ will essentially remain constant over that interval of cycles and present a certain constant intrinsic threshold, $K_{\text {th }}$. Even in this case though, $\sigma^{*}$ would still have been influenced by prior load history. Unchanged $\mathrm{K}_{\mathrm{th}}$ only implies lack of hysteresis induced cycle-by-cycle variation in $\sigma^{*}$ combined with $\mathrm{K}_{\mathrm{op}}$ clipping the effect of possible variation in $\mathrm{K}_{\min }$. By no means does it imply the absence of load history effect on $\mathrm{K}_{\mathrm{th}}$.

Importantly, $\mathrm{K}_{\text {th }}$ represents an incremental, not an absolute value. As indicated by $\mathrm{K}_{\min }$ marking the origin of Fig 4, onset of threshold crack extension in a rising load half-cycle will coincide with applied K exceeding the sum $\left(\left(\mathrm{K}_{\mathrm{op}}\right.\right.$ or $\left.\left.\mathrm{K}_{\mathrm{min}}\right)+\mathrm{K}_{\mathrm{th}}\right)$. How much exactly the crack will extend during the remaining fraction of the tensile load half-cycle will be affected by interaction of two or more mechanisms. The first of these is the environment and diffusion kinetics driven reduction in material resistance to micro fracture [23] and the second is rising driving force towards Mode II (shear driven) crack extension. The contribution of the first will of course progressively recede with increasing $\Delta \mathrm{K}$ and at some point, it will be rendered totally irrelevant. The next section discusses how this aspect may be appropriately accounted for in the crack growth rate equation.

\section{Incorporation of $\mathbf{K}_{\mathrm{th}}$ into the Crack Growth Rate Equation}

To be of value in engineering application, the crack growth rate equation should correctly describe crack extension during an applied load cycle that may vary by as much as seven orders of magnitude. The gradual transition of crack growth rates from threshold conditions to a magnitude where threshold resistance ceases to be relevant needs to be adequately described by the crack growth rate equation. Judging from Fig. 4b and assuming fatigue crack extension occurs during the rising load half-cycle, the first point of interest in the load cycle is $\mathrm{K}_{\mathrm{op}}$. At $\mathrm{K}_{\mathrm{op}}$, the crack-tip 'does not know' by how much $\mathrm{K}$ will increase beyond this point. However, because $\sigma^{*}$ is known, so is $\mathrm{K}_{\text {th }}$ that represents the incremental $\mathrm{K}$ required for the crack to extend by $10^{-7} \mathrm{~mm}$. One may assume that this crack extension is the direct consequence of crack-tip surface diffusion kinetics associated with the rising magnitude of near-tip stress, combined with incremental crack-tip deformation.

$\mathrm{K}_{\text {th }}$ can vary significantly in atmospheric fatigue depending on load history, $\mathrm{K}_{\max }$, etc. However, this being a crack-tip surface diffusion kinetics driven phenomenon, its significance will diminish with increasing contribution of crack extension by competing processes induced by the mechanics of crack tip response and associated crack growth once $\mathrm{K}$ exceeds $K_{\mathrm{op}}$. Thus, whilst crack extension at $10^{-6} \mathrm{~mm} /$ cycle will be almost certainly influenced by $\mathrm{K}_{\mathrm{th}}$, it is unlikely crack extension at $10^{-3} \mathrm{~mm} /$ cycle will see the effect of $\mathrm{K}_{\mathrm{th}}$, irrespective, of whether $\mathrm{K}_{\mathrm{th}}$ for the given load cycle is small or large. At this point, it may not be appropriate to assume that da/dN is driven by the difference, $\Delta \mathrm{K}_{\mathrm{eff}}-\mathrm{K}_{\mathrm{th}}$. 
As $K$ progressively increases beyond $\mathrm{K}_{\mathrm{op}}+\mathrm{K}_{\mathrm{th}}$, the significance of the $\mathrm{K}_{\mathrm{th}}$ component must be seen to progressively diminish as crack extension will be increasingly driven by a different mechanism altogether and increasingly sensitive only to $\Delta \mathrm{K}_{\text {eff }}$. This is particularly important, given the relationship between $\mathrm{K}_{\mathrm{th}}$ and $\sigma^{*}$. With increasing $\Delta \mathrm{K}$, while incremental near-tip stress towards $\mathrm{K}_{\max }$ is attenuated by inelasticity, elastic unloading over twice the yield stress over the same $\Delta \mathrm{K}$ will inevitably lead to lower $\sigma^{*}$ and increasing $\mathrm{K}_{\mathrm{th}}$ over the next loading half-cycle! This is illustrated by Fig. 5a and by the broken line in Fig. 5b. Theoretically, $K_{\text {th }}$ in the Paris Regime will approach the highest possible values in the $K_{\text {th }}$ versus $\sigma^{*}$ relationship. The receding significance of instantaneous $K_{\text {th }}$ in the face of rising $\Delta K$ may be accounted for by a certain effective $K_{\text {th }}$ denoted as $K_{\text {th,eff }}$ as described by the following equation valid over the range $K_{\text {th }}<\Delta K_{\text {eff }}<$ $K_{\text {eff }}^{*}$ :

$K_{t h, e f f}=K_{\mathrm{th}}\left[\frac{\left(K_{\mathrm{eff}}^{*}-K_{\mathrm{eff}}\right)}{\left(K_{\mathrm{eff}}^{*}-K_{\mathrm{th}}\right)}\right]^{p}$
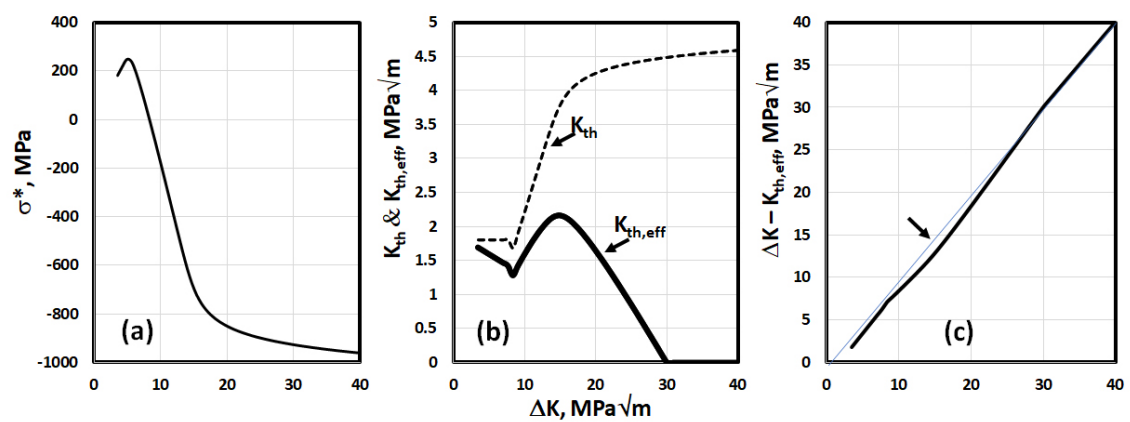

where, $K_{\text {eff }}^{*}$ is $\Delta \mathrm{K}_{\text {eff }}$ associated with a growth rate of $10^{-3} \mathrm{~mm} /$ cycle and 'p' is a constant, assumed for brevity to be unity. The form of this equation meets boundary conditions associated with both threshold as well as with the total disappearance of near-threshold response at $\Delta \mathrm{K}_{\mathrm{eff}}>=K_{\text {eff }}^{*}$. This is illustrated by the continuous line in Fig. 5b. Note that the momentary increase in $\mathrm{K}_{\mathrm{th} \text {,eff }}$ seen is due to initial rapid increase in $\mathrm{K}_{\mathrm{th}}$ caused by elastic unloading. However, $\Delta \mathrm{K}$ rises even more rapidly, with the difference between the two only showing a small recess as pointed by the arrow in Fig. 5c. One may speculate that such a recess may be the cause for the non-linearity or momentary 'flattening' in growth rate sometimes observed in experimental data at growth rates just below the Paris Regime.

One may expect that expected that $K_{\text {eff }}^{*}$, being associated with the Paris Regime, will always exceed $K_{\text {th }}$. Actual value of 'p' is likely to be determined by the competition of the two crack extension mechanisms involved. Determination of a more suitable value for 'p' can be the subject of future work. However, judging from forthcoming empirical evidence, $\mathrm{p}=1$ appears reasonable.

$\mathrm{K}_{\text {th }}$ is computed as a dependent variable of $\Delta \mathrm{K}_{\text {eff }}$ and associated $\mathrm{K}_{\max }$ from the $\mathrm{K}_{\text {th }}$ versus $\sigma^{*}$ relationships as shown in Fig. 1. Under constant amplitude loading, the computed value of $\mathrm{K}_{\text {th }}$ will be valid for a given stress ratio and known crack closure. Under near threshold conditions defined by the condition $\Delta \mathrm{K}_{\text {eff }}<$

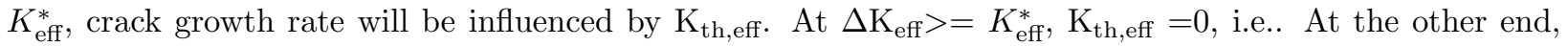
as $K_{\max }$ approaches $K_{c}$, increasing contribution of quasi static component from local fracture by microvoid coalescence, strain localization across brittle constituents, etc will accelerate growth. An equation that describes this entire range of growth rate may be assumed to take the form:

$$
\begin{aligned}
& \frac{\mathrm{da}}{\mathrm{dN}}=C\left[K_{\mathrm{eff}}-K_{t h, e f f}\right]^{m} \frac{1}{\left(1-\frac{K_{\max }}{K_{c}}\right)^{q}}, K_{\mathrm{eff}}<K_{\mathrm{eff}}^{*}(5) \\
& \frac{\mathrm{da}}{\mathrm{dN}}=C\left[K_{\mathrm{eff}}\right]^{m} \frac{1}{\left(1-\frac{K_{\max }}{K_{c}}\right)^{q}}, K_{\mathrm{eff}} \geq K_{\mathrm{eff}}^{*}(6)
\end{aligned}
$$

where, $\mathrm{K}_{\mathrm{c}}$ is fracture toughness and ' $\mathrm{q}$ ' is a constant assumed for brevity to be unity. The correction of 
da/dN to account for $K_{\max }->K_{c}$ is the same as that adopted widely in the literature. Eq. (6) is essentially the same as eq. (5) with the exception that $\mathrm{K}_{\mathrm{th}, \mathrm{eff}}=0$.

Note that eq. (5) is limited to da/dN $>=10^{-7} \mathrm{~mm} /$ cycle. As engineering practice constantly pushes the demands on durability and residual crack growth life to higher cycle counts, $K_{\text {th }}$ will arguably also require reconsideration in terms of associated da/dN. For engineering purposes, one may extend $\mathrm{K}_{\text {th }}$ at $10^{-7}$ down to $10^{-9} \mathrm{~mm} /$ cycle by correction of its value given the slope of da/dN curve at $10^{-7} \mathrm{~mm} /$ cycle.

We now proceed to summarise the procedure to determine the material constants in eq. 5 .

\section{Material Constants \& Validation}

Obviously, a number of material constants are involved in forming an equation that attempts to describe variation of crack growth rate over seven orders of magnitude. Particularly so, when the 'origin' of the $\mathrm{da} / \mathrm{dN}$ curve corresponding to threshold $\mathrm{da} / \mathrm{dN}$ of $10^{-7} \mathrm{~mm} /$ cycle is itself highly sensitive to $\sigma^{*}$. $\sigma^{*}$ in turn is determined using constants that describe the cyclic stress-strain curve. Near-threshold crack growth rates will depend on $\mathrm{K}_{\mathrm{th}}$ as well as the emerging dominance of the Paris Regime parameters $\mathrm{C}$ and $\mathrm{m}$. Finally, the addition of quasi-static component from the proximity of fracture will accelerate growth rate as $\mathrm{K}_{\max }$ approaches $\mathrm{K}_{\mathrm{c}}$.

Computation of near-tip stress response leading to the characterization of the $K_{\text {th }}$ versus $\sigma^{*}$ relationship requires constants defining the cyclic stress-strain curve of the material, namely, Young's Modulus, E, cyclic strength coefficient, K', and cyclic strain hardening exponent, n' (see Fig. 2).

A realistic evaluation of the new framework involves an attempt to correlate experimental data over the entire range of associated crack growth rates, i.e., from $10^{-7}$ to $10^{-1} \mathrm{~mm} / \mathrm{cycle}$. Such a correlation can be assessed by plotting data in the log-log scale as $\frac{\mathrm{da}}{\mathrm{dN}}\left(1-\frac{K_{\max }}{K_{c}}\right)$ against $K_{\mathrm{eff}}-K_{t h, e f f}$. A good fit would be indicated by a linear fit with slope, ' $\mathrm{m}$ ' and intercept, $\mathrm{C}$.

Experimental data obtained on Ti-6Al-4V in the course of this data were consolidated using the above framework. All the required tests were performed at BISS Labs on a BISS $25 \mathrm{kN}$ high performance servohydraulic test system permitting test frequency of up to $250 \mathrm{~Hz}$. The tests were performed on $5 \mathrm{~mm}$ thick, $50 \mathrm{~mm}$ wide $\mathrm{C}(\mathrm{T})$ specimens, with test frequency set to $100 \mathrm{~Hz}$ to ensure amplitude error less than $1 \%$. Two of the specimens were tested to determine $K_{\text {th }}$ values under a wide range of $\sigma^{*}$. The crack growth curves from these tests appear as Fig. 6 .

The test procedure to characterize the $\mathrm{K}_{\mathrm{th}}$ versus $\sigma^{*}$ relationship is described in detail elsewhere $[18,19,27]$. The determination of each data point in Fig. 3 involved gradual reduction in crack growth rate over a few million load cycles of progressively reducing $\Delta \mathrm{K}$ in decrements of $10 \%$. These sets of transient data covering a reasonably wide range of growth rate are consolidated as da/dN versus $\Delta \mathrm{K}$ in Fig. 7. Given the nature of the transients involving cycling at $\mathrm{P}_{\max }=$ Const and steadily increasing $\mathrm{P}_{\min }$ to impose receding $\Delta \mathrm{K}$, the stress ratio associated with individual data points invariably increases with reducing crack growth rate, reaching up to values in excess of $\mathrm{R}=0.8$. Also shown in Fig. 7 are data from a single constant amplitude test performed at stress ratio $\mathrm{R}=0.3$ and assumed to involve little or no crack closure. For the same reason, $\Delta \mathrm{K}$ may be treated as $\Delta \mathrm{K}_{\mathrm{eff}}$ for these data. 

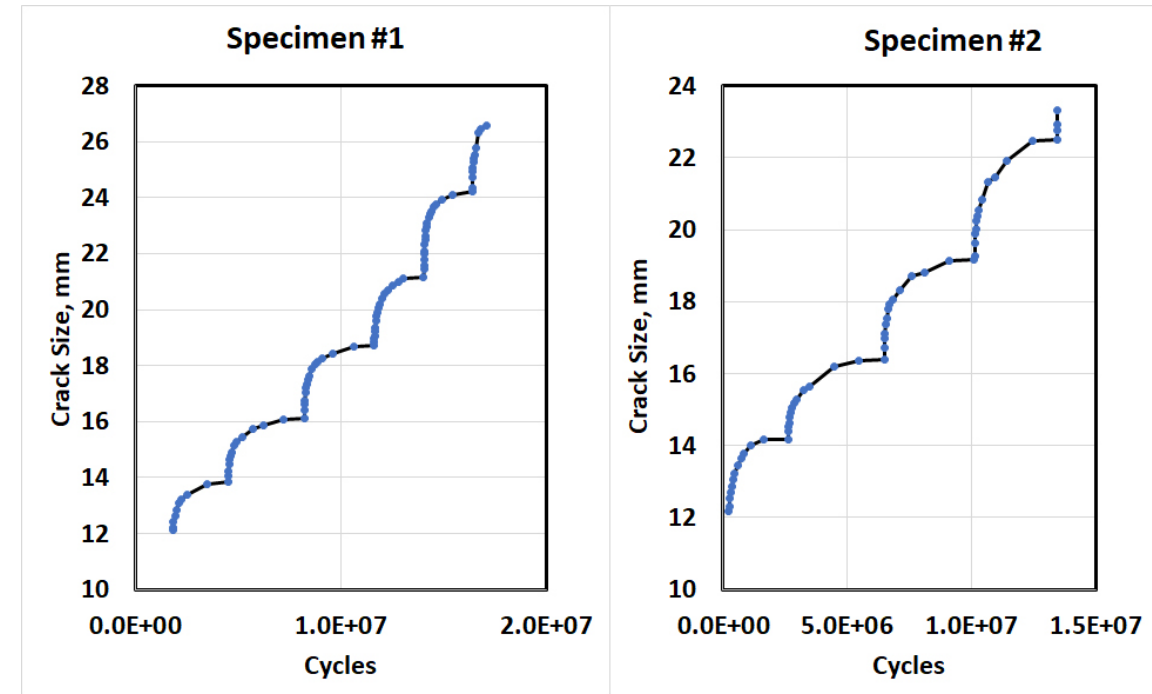

The data in Fig. 7 are plotted as $\frac{\mathrm{da}}{\mathrm{dN}}\left(1-\frac{K_{\max }}{K_{c}}\right)$ against $K-K_{t h, e f f}$. Also shown in the figure is a trend line suggesting a slope $\mathrm{m}=2$ over the data range.

\section{DISCUSSION}

The discovery of crack closure was a turning point in understanding stress ratio and load interaction effects in fatigue crack growth. Establishment of the unique relationship between $K_{\text {th }}$ and $\sigma^{*}$ may serve as the next turning point by explaining why significant load interaction effects will persist even in the absence of crack closure, and why, the significance of these effects increases disproportionately into near-threshold fatigue, that dominates in the HCF and VHCF domains.

By drawing the line between propagating and non-propagating cracks, thresholds effectively determine fatigue limit. In doing so, the new understanding also provides a fundamental explanation as to why fatigue limit diminishes with mean stress, a phenomenon known (albeit unexplained) for more than 150 years from the pioneering work of Wohler And Bauschinger [35, 36]. 


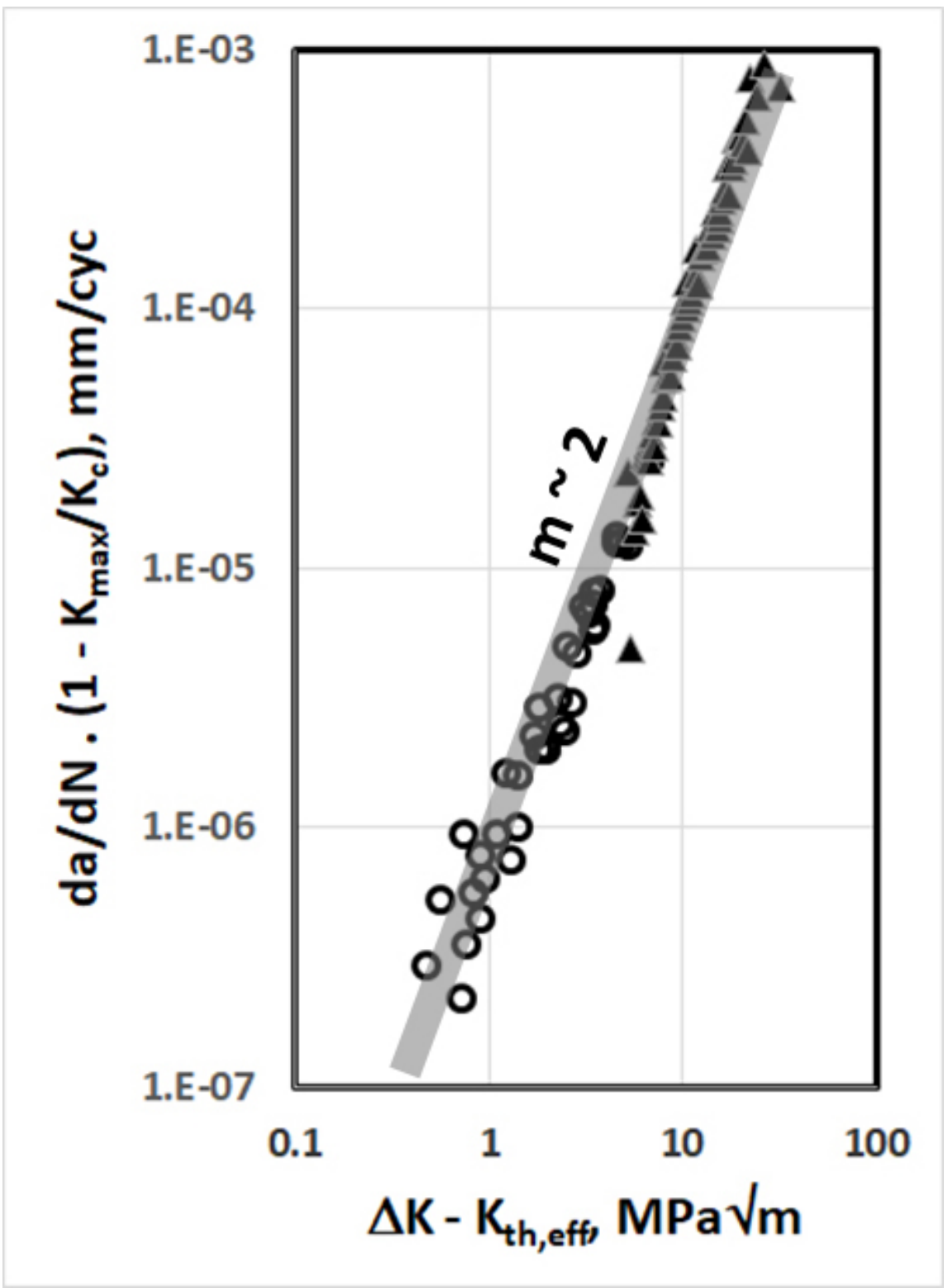

The new procedure to determine the relationship between $\mathrm{K}_{\mathrm{th}}$ and $\sigma^{*}$ suggests more conservative estimates of $\mathrm{K}_{\mathrm{th}}$ than would follow from conventional testing practice. To cite an example of consequences for engineering application to naturally forming cracks, given the estimates obtained on Ti-6Al-4V, it would follow that the potential minimum size of cracks that can propagate at a given applied stress level would be less than half the size expected from the lowest $\Delta \mathrm{K}_{\mathrm{th}}$ estimates from conventional testing practice. This, given the square root dependence of $\mathrm{K}$ on crack size.

The $\mathrm{K}_{\mathrm{th}}$ versus $\sigma^{*}$ relationship appears to lay to rest misunderstandings caused by prevailing testing practices to characterize fatigue thresholds, that resulted in attempts to relate $\Delta \mathrm{K}_{\mathrm{th}}$ to $\mathrm{K}_{\max }$, R-ratio, etc,. Obviously, given a certain partial pressure of active species and rate of loading, the degree of BMF in a single rising load half cycle would be determined by the extent of their surface diffusion. The associated diffusion kinetics at a given temperature will be moderated by a certain instantaneous near-tip hydrostatic or biaxial stress as it increases from that, at the commencement of the rising load half cycle, i.e., from $\sigma^{*}$. For this reason, 
$\mathrm{K}_{\text {th }}$ correlates with near-tip stress at the commencement of the rising half of the load cycle, rather than at $\mathrm{K}_{\max }$. Strictly speaking, this stress should not be referred to as 'residual' because by 'residual' one would imply stress at no load. However, the two would be synonymous if $\mathrm{K}_{\min }<=\mathrm{K}_{\mathrm{op}}$, as near-tip stress response can be assumed to cease below $\mathrm{K}_{\mathrm{op}}$.

It has for long been wrongly assumed, that by accounting for crack closure and other shielding effects, laboratory constant amplitude crack growth rate data can be extended to variable-amplitude loading. While closure does indeed go a long way in bridging the gap, its ability to do so becomes increasingly diluted in the near-threshold region leading down to threshold. This gap extends to a three order of magnitude variation in crack growth rate, where instantaneous $\mathrm{K}_{\mathrm{th}}$ comes into play. Closure can at best account for the extrinsic component of $\Delta \mathrm{K}_{\mathrm{th}}$. The intrinsic component is uniquely related to near-tip residual stress, a parameter that like closure, is also sensitive to crack tip mechanics, but in ways that are very different from crack closure. Unlike crack closure, near-tip residual stress is cycle-sequence sensitive. Unlike crack closure, it can exhibit cycle-to-cycle bi-directional variation and do so, even without requiring crack extension. While crack closure is largely wake driven, near-tip stress variation requires an open crack.

The form of the modified equation (5) for da/dN accounts for the manner in which growth rate transits from threshold into the Paris Regime. Further, the relationship between $\mathrm{K}_{\mathrm{th}}$ and $\sigma^{*}$ combined with the treatment of $K_{t h}$ as a cycle-sequence sensitive variable in the equation opens up the possibility of modeling variable-amplitude fatigue from its very early stages. Thus, variable-amplitude fatigue crack growth can be modeled as a consequence of the combined action of crack closure and crack-tip blunting on the one hand and on the other, by the effect of these on $\sigma^{*}$ on a cycle-by-cycle basis. Such a 'tri mechanism' or 'TriM' model was successfully applied to model residual crack propagation lives in the range 5 to 20 million cycles for 2024-T3 alloy under an extended duration transport aircraft load spectrum [37]. A fractographic study of the failures obtained revealed significant load sequence sensitive variations in fatigue crack extension during the large fraction of smaller load cycles. These were adequately modeled by correcting $\mathrm{K}_{\mathrm{th}}$ over these cycles as a function of load history. There are hardly any data in the literature reflecting attempts to model residual life exceeding even a million cycles, suggesting limitations posed by the lack of threshold data suitable for engineering application.

Unlike closure that develops early and persists throughout the crack growth process and is rather independent of the mechanisms that drive crack extension, intrinsic threshold fades into vanishing proportions as da/dN exceeds $10^{-4} \mathrm{~mm} /$ cycle. For this reason, both load interaction effects as well as environment related effects affected by $K_{t h}$ will fade away with increasing growth rate. The latter was clearly brought out in early experiments by Bradshaw and Wheeler on the influence of test frequency and partial pressure of moisture on crack growth rates [38]. These highlighted the increasing effect of both test frequency and partial pressure of moisture with decreasing crack growth rate. It follows that if growth rates below the Paris Regime are involved, prevailing approaches to laboratory data generation and modeling are limited in their ability to come up with residual life estimates of value to engineering practice. Besides, given the vast difference in the physics behind crack closure and near threshold response, one cannot hope to 'fudge' the effect of the latter through distorted simulation of the former.

Load interaction effects have also been modeled by simulating mean stress variation in the cyclic plastic zone using a cumulative damage approach [39]. However, such an approach, just as also, the two-parameter approach [14] do not focus on the phenomenon in question, namely, the influence of near-tip stress on threshold response. They are faulted in wrongly assuming that the effect persists across the entire range of growth rates.

Most of fatigue life is exhausted in the early stages of fatigue crack growth. As non-destructive inspection technologies improve, smaller fatigue cracks can be detected to permit increased service life between inspections. The potential for induction of additive manufactured components in safety critical applications can benefit greatly from the ability to estimate the residual life assuming pre-existing defects associated with the $3 \mathrm{D}$ printing process. All these imply a rising demand for capability to estimate residual crack growth life in the HCF and VHCF regimes. Obviously, this is less likely to materialize without the ability to model $\mathrm{K}_{\mathrm{th}}$ 
variation along with other load interaction mechanisms such as closure. Analytical modeling of $\mathrm{K}_{\mathrm{th}}$ under variable-amplitude loading, combined with that of crack closure appears to be a potentially rewarding area of future research.

Discovery of the close connection between near-threshold fatigue crack growth behavior and near-tip residual stress raises new questions and opens new avenues in fatigue research of direct application value. An important new avenue of fundamental research is the search for an analytical connection between partial pressure of active species such as moisture in air and oxygen at high temperature, rate of loading (or frequency) and the relationship between $K_{\text {th }}$ and $\sigma^{*}$. One would expect a lateral shift in this relationship, whose model would significantly reduce the cost of future testing effort. An even more significant impact of engineering value would be the development of engineered materials with improved resistance to surface diffusion of active species.

The new findings are also likely to impact a new interpretation of near-threshold region of sustained load cracking. Thus, it is likely that if service loading involves hold-time at an intermediate load level, one would have to consider the hysteretic variation in near-tip stress depending on whether such hold time occurs on the rising or falling half of a major load cycle.

From the standpoint of immediate application, an important question relates to the definition of $\mathrm{r}^{*}$. In previous work, the goal was to select a value that provides the best correlation between $K_{\text {th }}$ and $\sigma^{*}$. It is not clear whether $\mathrm{r}^{*}$ thus selected will also deliver the best estimates of variable amplitude fatigue crack growth life, when cycle-by-cycle correction of $\mathrm{K}_{\mathrm{th}}$ is resorted to as a function of $\sigma^{*}$, computed at a given $\mathrm{r}^{*}$ for a given service load sequence. Another relates to the choice of cyclic-stress strain curve. $\mathrm{K}^{\prime}$ and n' in this study were based on tests on smooth specimens. However, they are applied to a point ahead of the crack tip that is likely to see the effect of constraint, where K' and n' are likely to be different. Strictly speaking, r* should be zero. However, analysis treats the crack tip to be a singularity, that in itself, is an approximation. Notwithstanding this contradiction, the consistent and reproducible relationship between $\mathrm{K}_{\text {th }}$ and $\sigma^{*}$, seen in all the materials that were tested testifies to its uniqueness and reproducibility. It also suggests the apparent irrelevance of $\mathrm{K}_{\max }$ and stress ratio that have served testing practice for all these years.

Finally, naturally forming small cracks will be sensitive to local phenomena as induced by microstructure such as grain size, grain boundary orientation and local mechanical property variations [40], that go beyond the scope of this study. The important question is whether such cracks will grow, or, get arrested. It now emerges, that in atmospheric fatigue, in addition to the three threshold states highlighted by Miller, instantaneous $\mathrm{K}_{\mathrm{th}}$ as affected by loading conditions including load history plays a major role in controlling the fate of naturally forming small cracks that eventually determines durability.

\section{CONCLUSIONS}

1. $\mathrm{K}_{\mathrm{th}}$, the intrinsic component of $\Delta \mathrm{K}_{\mathrm{th}}$, is sensitive to a certain, computable, near-tip residual stress, $\sigma^{*}$, whose variation can be analytically described for a given load history, based on a material's cyclicstress strain response. This enables accounting for significant load history effect on $\mathrm{K}_{\mathrm{th}}$, that hitherto appears to have been wrongly considered to be a material constant.

2. Experiments on Ti-6Al-4V test coupons show variations in $\mathrm{K}_{\text {th }}$ between 1.25 and $4.3 \mathrm{MPa}[?] \mathrm{m}$, in what appears to be a unique relationship with $\sigma^{*}$. This trend and nature of relationship is similar to that, observed on several other materials that showed a variation up to a factor of five.

3. A method is proposed to separate intrinsic and extrinsic components of $\Delta K_{\text {th }}$ from legacy data bases of $\Delta \mathrm{K}_{\mathrm{th}}$. Such a separation enables the application of $\Delta \mathrm{K}_{\mathrm{th}}$ obtained on long cracks under load shedding, to engineering problems, involving small and naturally forming cracks growing under service loading conditions.

4. An equation is proposed for crack growth rate that accounts for variations in $K_{t h}$ in the transient region between threshold and the Paris Regime. This equation appears to show good correlation of near-threshold crack growth rates obtained from tests on Ti-6Al-4V test specimens. It can be used to account for effects of both load ratio as well as load history in engineering estimates of residual fatigue 
life extended into the HCF and VHCF regimes.

5. The unique relationship between $\mathrm{K}_{\mathrm{th}}$ and $\sigma^{*}$ appears to represent a scientific explanation for the residual stress effect on naturally forming small cracks growing in the absence of closure.

Acknowledgement: The authors are grateful to Air Force Research Laboratories (AFRL), WPAFB-OH, USA and University of Dayton, for the provision of Ti-6Al-4V C(T) test specimens. The tests were carefully performed by Meghanathan.

\section{REFERENCES}

1. ASTM E647-15e1, Standard Test Method for Measurement of Fatigue Crack Growth Rates, ASTM International, West Conshohocken, PA, 2015, www.astm.org

2. Elber, W., "The Significance of Fatigue Crack Closure," Damage Tolerance in Aircraft Structures, ASTM STP 486, ASTM International, West Conshohocken, PA, 1971, pp. 230-242.

3. Ritchie, R.O., Davidson, D.L., Boyce, B.L., Campbell, J.P., and Roder, O., High-cycle fatigue of Ti-6Al-4V, Fatigue Fract Engng Mater Struct 22, 621-631

4. Vasudevan, A.K., Suresh, S., 1982. Influence of corrosion deposits on near-threshold fatigue crack growth behavior in 2xxx and 7xxx series aluminum alloys. Metallurgical and Materials Transactions A $13,2271-2280$

5. Suresh, S., Zamiski, G.F., Ritchie, R.O., Oxide-Induced Crack Closure: An Explanation for NearThreshold Corrosion Fatigue Crack Growth Behavior, Metallurgical Transactions A, Volume 12A, Aug 1981, pp. 1435-1443

6. Newman, J.C., Schneider, J., Daniel, A., McKnight, D., Compression pre-cracking to generate nearthreshold fatigue-crack-growth rates in two aluminum alloys. International Journal of Fatigue 27, 2005, 1432-1440.

7. Newman, J.C., Yamada, Y., Compression pre-cracking methods to generate near-threshold fatiguecrack-growth-rate data. International Journal of Fatigue 32, 2010, 879-885.

8. Smith, S.W., Seshadri, B. R. and Newman, J.A., Experimental and Finite Element Modeling of NearThreshold Fatigue Crack Growth for the K-decreasing Test Method, $15^{\text {th }}$ International Symposium on ASTM/ESIS Symposium on Fatigue and Fracture Mechanics, May 20-22 2015, Anaheim, CA.

9. Tanaka, K. and Akiniwa, Y., Resistance-Curve Method for Predicting Propagation Threshold of Short Fatigue Cracks at Notches, Engineering Fracture Mechanics, Vol 30, No 6, pp. 863-876, 1988

10. Maierhofer, J., Kolitsch, S., Pippan, R., Gänser, H., Madia, M., Zerbst, U., The cyclic Rcurve - Determination, problems, limitations and application, Engg Fract Mech (2017), https://doi.org/10.1016/j.engfracmech.2017.09.032.

11. Lawson, L., Chen, E.Y., Meshii, M., Near-threshold fatigue: a review, Int. J. Fatigue, 21, 1999, pp S15-S34.

12. Taylor D. A compendium of fatigue thresholds and growth rates. Engineering Materials Advisory Services Ltd., West Midlands, UK, 1985.

13. Boyce, B.L., and Ritchie, R.O., Effect of load ratio and maximum stress intensity on the fatigue threshold in Ti-6Al-4V, Engineering Fracture Mechanics, 68, 2001, pp 129-147.

14. Vasudevan AK, Sadananda K, Louat N., Two critical stress intensities for threshold crack propagation. Scr Metall 1993;28:65-70.

15. Vasudevan AK, Sadananda K, Holtz, R.L., Extension of the Unified Approach to fatigue crack growth to environmental interactions, Int. J. Fatigue, 23, 2001, pp S277-S286.

16. Vasudevan AK, Sadananda K, Louat N., A review of crack closure, fatigue crack threshold and related phenomena, Materials Science and Engineering, A188, 1994, pp. 1-22.

17. Vasudevan AK, Sadananda K,, Application of unified damage approach to compression-tension region, Int. J. Fatigue, 21, 1999, S263-S273

18. Sunder, R., Characterization of Threshold Stress Intensity as a Function of Near-Tip Residual Stress: Theory, Experiment, and Applications, Materials Performance and Characterization (An ASTM Journal), Vol 4, No 2, 2015, pp105-130.

19. Sunder, R., Koraddi, R., and Vishwas, C., Threshold Characterization to Support Residual Life Esti- 
mates Under Variable-Amplitude Service Loading, Presented at ASTM Annual Symposium on Fatigue and Fracture, Denver, May 15-17, 2019, under consideration of publication .

20. Sunder R., On the hysteretic nature of variable-amplitude fatigue crack growth, Int J. Fatigue, 2005, Vol 27, pp 1494-1498

21. Sunder, R., Porter, W.J., and Ashbaugh, N.E., The Role of Air in Fatigue Load Interaction, Fatigue Fract Engng Mater Struct, 26, 2003, pp. 1-16.

22. Ashbaugh, N.E., Porter, W.J., Rosenberger, A.H., and Sunder, R., Environment -Related Load History Effects in Elevated Temperature Fatigue of a Nickel-Base Super-alloy, Proc., Fatigue 2002, Stockholm, June 2-7, EMAS (2002).

23. Sunder, R., Fatigue crack growth as a consequence of environment-enhanced brittle-micro fracture, Fatigue Fract. Engng. Mater. Struct ., 28 (3) (2005) pp. 289-300.

24. Ro, Y., Agnew, S. R., and Gangloff, R. P., "Environmental Fatigue-Crack Surface Crystallography for Al-Zn-Cu-Mg-Mn/Zr," Metall. Mater. Trans. A, Vol. 39A, 2008, pp. 1449-1465.

25. Y. Murakami, T. Kanezaki, Y. Mine, S. Matsuoka, Hydrogen embrittlement mechanism fatigue of austenetic stainless steels. Metall. Mater. Trans. A 39, 1327 (2008)

26. Sunder, R., Unraveling the Science of Variable-Amplitude Fatigue, Journal of ASTM International, Vol. 9, No. 1, Paper ID JAI103940, 2012. Also, ASTM Special Technical Publication 1546, 2012, pp. $20-64$.

27. Sunder, R., Koraddi, R., and Gorunov, A., Characterization of Intrinsic Fatigue Threshold for Additive Manufactured Materials, submitted for publication in ASTM STP 1631, 2020.

28. Wheeler, O. E., "Spectrum Loading and Crack Growth," ASME J Basic Eng., Vol. 94, 1972, pp. $181-186$.

29. Willenborg, J., Engle, R. H., and Wood, H. A., "A Crack Growth Retardation Model Based on Effective Stress Concepts," Report No. AFFDL-TM-71-1 FBR, WPAFB, OH, 1971.

30. Hill, M.R., VanDalen, J.E., Prime, M.B., Measurements of Residual Stress in Fracture Mechanics Coupons, American Society of Mechanical Engineers, Pressure Vessels and Piping Division (Publication) PVP 6:251-257, 2011, DOI: 10.1007/978-1-4419-9792-0_41

31. Diana A. Lados, D.A., Apelian, D., Keith Donald, J., Fracture mechanics analysis for residual stress and crack closure corrections, International Journal of Fatigue 29 (2007) 687-694

32. Bowles, C. Q., 1978, "The Role of Environment, Frequency and Wave Shape During Fatigue Crack Growth of Aluminum Alloys," Ph.D. thesis, Report No. LR-270, Delft Univ. of Technology, Delft, The Netherlands.

33. Petit, J., Henaff, G., and Sarrazin-Baudoux, C., "Mechanisms and Modeling of Near-Threshold Fatigue Crack Propagation, Fatigue Crack Growth Thresholds, Endurance Limits and Design," ASTM Spec. Tech. Publ., J. C. Newman, Jr. and R. S. Piascik, Eds., Vol. 1372, American Society for Testing and Materials, West Conshohocken, PA, 2000.

34. Kitagawa H, and Takahashi S, in Proc. Second Int. Conf. onMechanical Behavior of Materials, ASM, Metals Park, Ohio (1976) p. 627

35. Wohler, A., Uber die Festigkeitsversuche mit Eisen und Stahl, Berlin, Ernst und Korn, 1870.

36. Anon, "Wo"hler's Experiments on the strength of Metals," Engineering, Vol. 4, 1867, pp. 160-161.

37. Sunder, R., Towards Improved Modeling of Variable-Amplitude Fatigue Crack Growth-Theory and Fractographic Validation, in Structural Integrity Assessment, Lecture Notes in Mechanical Engineering (R. V. Prakash et al. (eds.),), Springer Nature Singapore Pte Ltd. 2020, https://doi.org/10.1007/978981-13-8767-8_1

38. Bradshaw, F. J. and Wheeler, C., "The Effect of Gaseous Environment and Fatigue Frequency on the Growth of Fatigue Cracks in Some Aluminium Alloys," Int. J Fract. Mech., Vol. 6, 1969, pp. 255-268.

39. Mikheevsky, S., and Glinka, G., Elastic-plastic fatigue crack growth analysis under variable amplitude loading, Int. J. Fatigue, 31 (2009) 1828-1836.

40. Miller, K.J., The three thresholds for fatigue crack propagation, ASTM STP 1296, American Society for Testing and Materials, 1997, pp. 267-286. 